\title{
molecules
}

ISSN 1420-3049

www.mdpi.com/journal/molecules

Article

\section{Concise Synthesis of Broussonone A}

\author{
Hyeju Jo ${ }^{1}$, Minho Choi ${ }^{1}$, Mayavan Viji ${ }^{1}$, Young Hee Lee ${ }^{1}$, Young-Shin Kwak ${ }^{2, *}$, Kiho Lee ${ }^{2}$, \\ Nam Song Choi ${ }^{3}$, Yeon-Ju Lee ${ }^{4}$, Heesoon Lee ${ }^{1}$, Jin Tae Hong ${ }^{1}$, Mi Kyeong Lee ${ }^{1}$ \\ and Jae-Kyung Jung 1 ,*
}

1 College of Pharmacy and Medicinal Research Center (MRC), Chungbuk National University, Cheongju 362-763, Korea; E-Mails: hjjo317@chungbuk.ac.kr (H.J.); entia727@chungbuk.ac.kr (M.C.); cheviji@gmail.com (M.V.); yhlee91@daum.net (Y.H.L.); medchem@chungbuk.ac.kr (H.L.); jinthong@chungbuk.ac.kr (J.T.H.); mklee@chungbuk.ac.kr (M.K.L.)

2 College of Pharmacy, Korea University, Sejong 339-700, Korea; E-Mail: kiholee@korea.ac.kr

3 College of Interdisciplinary \& Creative Studies, Konyang University, Nonsan 320-711, Korea; E-Mail: nschoi@konyang.ac.kr

4 Korea Ocean Research and Development Institute, Ansan 426-44, Korea; E-Mail: yjlee@kordi.re.kr

* Authors to whom correspondence should be addressed; E-Mails: youngshin@korea.ac.kr (Y.-S.K.); orgjkjung@chungbuk.ac.kr (J.-K.J.); Tel.: +82-44-860-1622 (Y.-S.K.); +82-43-261-2635 (J.-K.J.); Fax: +82-43-268-2732 (J.-K.J.).

Academic Editor: Joshua G. Pierce

Received: 3 August 2015 / Accepted: 25 August 2015 / Published: 2 September 2015

\begin{abstract}
A concise and expeditious approach to the total synthesis of broussonone A, a $p$-quinol natural compound, has been developed. The key features of the synthesis include the Grubbs II catalyst mediated cross metathesis of two aromatic subunits, and a chemoselective oxidative dearomatizationin the presence of two phenol moieties. Especially, optimization associated with the CM reaction of ortho-alkoxystyrenes was also studied, which are known to be ineffective for $\mathrm{Ru}$-catalyzed metathesis reactions under conventional reaction conditions because ortho-alkoxy group could coordinate to the ruthenium center, resulting in the potential complication of catalyst inhibition.
\end{abstract}

Keywords: broussonone A; cross metathesis; Grubbs catalyst; oxidative dearomatization; PIFA; total synthesis 


\section{Introduction}

Broussonone A (1), a p-quinol natural product, was first isolated by our group from stem barks of the Korean plant Broussonetia kanzinoki Sieb (Moraceae) [1]. This plant is one of the most abundant trees in Korea, which has been extensively used as diuretic or tonic agents [1-5]. Broussonone A (1) exhibited inhibitory activity on pancreatic lipase with $\mathrm{IC}_{50}$ of $28.4 \mu \mathrm{M}$. Due to its structural features (e.g., $p$-quinol moiety and unrevealed stereochemistry) and interesting biological property, broussonone A lends itself as a challenging synthetic target. To date, there has been no reported total synthesis of the broussonone A.

In planning our approach, we hoped to develop a versatile and practical route that would minimize protecting group manipulations and adapt a platform that leads to a variety of analogues of $\mathbf{1}$. Herein, we report a facile synthesis of $\mathbf{1}$ in three steps from readily available starting materials, enlisting a cross metathesis (CM) of two aromatic subunits and a chemoselective oxidative dearomatization of one of two phenol groups.

\section{Results and Discussion}

The crucial elements of our retrosynthetic analysis of broussonone A (1) are shown in Scheme 1. We envisioned that the late-stage generation of the para-quinol B ring could be achieved through a chemoselective oxidative dearomatization in the electron-rich subunit B of $\mathbf{2}$. The requisite intermediate $\mathbf{2}$ could be obtained by a Wittig reaction of the aldehyde $\mathbf{3}$ or CM of the styrenyl ether $\mathbf{4}$ with a corresponding olefin, respectively.

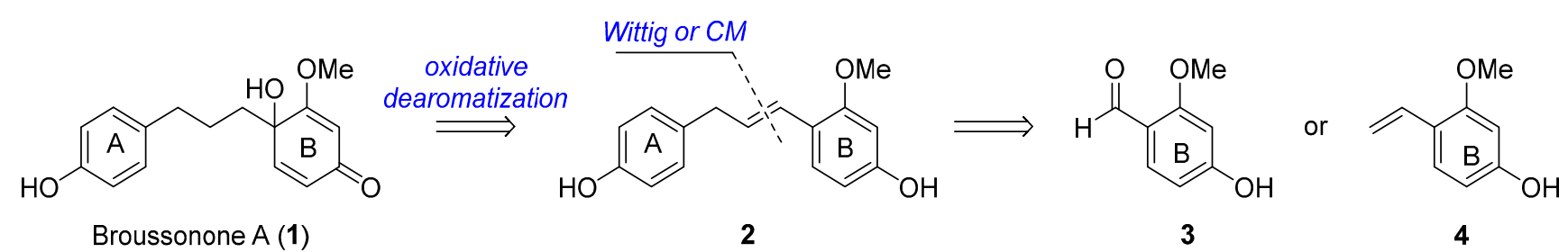

Scheme 1. Retrosynthetic approach of broussonone A (1).

In order to synthesize the compound 2, we commenced our investigation by employing a Wittig reaction between aldehydes 3 and the corresponding phosphonium salt $\mathbf{5}$, derived from the commercially available 2-(4-hydroxyphenyl) ethanol [6,7]. However, the Wittig reaction failed to afford our desired product $\mathbf{2}$ presumably due to low reactivity of the electron-rich benzaldehydes 3 (Scheme 2) [8].<smiles>[R]Oc1ccc(C=O)c(OC)c1</smiles>

3a $\mathrm{R}=\mathrm{H}$

3b $\mathrm{R}=\mathrm{Bn}$

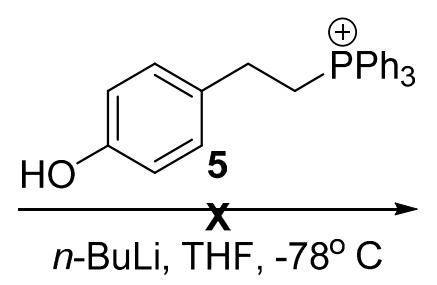

2a $R=H$
$2 b \quad R=B n$

Scheme 2. Wittig reaction to synthesize the key precursors 2. 
Having failed to access 2 through the Wittig reaction, we turned our attention to the CM strategy for the formation of $\mathbf{2}$. Grubbs catalysts have been recognized as more efficient and reliable complexes widely utilized in cross metathesis reaction for a variety of alkene chemistry [9-12]. However, ortho-alkoxystyrenes are known to be ineffective for Ru-catalyzed metathesis reactions under conventional reaction conditions because they could readily form the highly stable Ru-chelate complex 7 discouraging the catalytic cycle $[13,14]$. Despite the formidable challenge ahead, we were prompted to attempt the CM reaction between $\mathbf{4}$ and $\mathbf{6}$ utilizing a Grubbs protocol since it would be the most unambiguous and rapid access to the key intermediate $\mathbf{2}$ (Scheme 3 ).

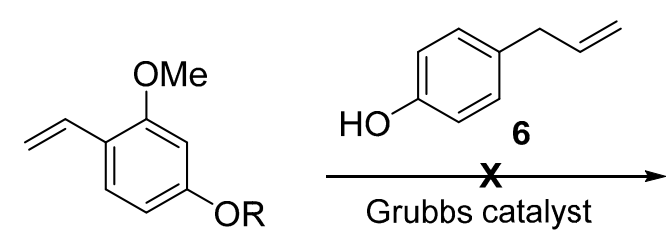

4a $\mathrm{R}=\mathrm{H}$

4b $\mathrm{R}=\mathrm{Bn}$<smiles>[R]Oc1ccc(/C=C/Cc2ccc(O)cc2)c(OC)c1</smiles>

2a $\mathrm{R}=\mathrm{H}$

2b $R=B n$

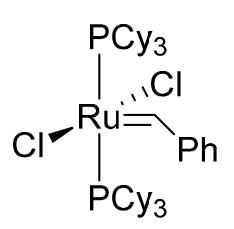

Grubbs I<smiles>CN1CCN(C)C1[R](Cl)(Cl)/C(Cl)=C/c1ccccc1</smiles>

Grubbs II

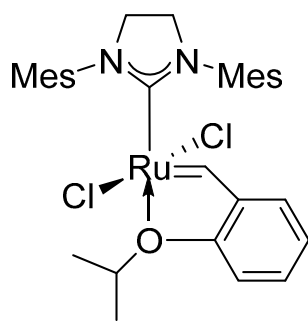

Hoveyda-Grubbs

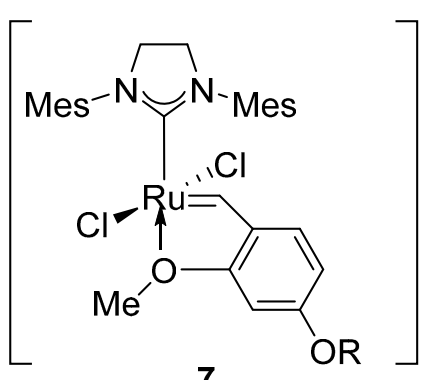

7

Scheme 3. Cross metathesis (CM) reaction of 2-alkoxy styrenes 4.

The allylphenol 6 was prepared following a literature procedure [15] and the 2-alkoxystyrene 4 was protected with a benzyl group. An initial CM attempt with the allylphenol $\mathbf{6}$ and 2-alkoxystyrenes $\mathbf{4}$ failed to provide the desired CM product and we observed the homodimer of $\mathbf{6}$ as the major product instead $[16,17]$. Thus, we were directed to use the homodimer $\mathbf{8}$ for the key CM reaction partner that was readily synthesized from 6 in 87\% yield utilizing Grubbs I catalyst (2 mol \%) [18,19].

Efforts were made to optimize the CM reaction outcome using $\mathbf{4 b}$ and $\mathbf{8}$ as summarized in Table 1. Several ruthenium catalysts were tested and to when the Grubbs II catalyst or the Hoveyda-Grubbs II catalyst were employed, gratifyingly we obtained desired product (entries 2-4) in low yields, whereas no product formation was observed when the Grubbs I catalyst was used (entry 1). While varying the amount of catalyst loading; we obtained the best results by using 5 mol \% Grubbs II catalyst (entry 4). Further increase of catalyst loading to $10 \mathrm{~mol} \%$ produced unfavorable results such as olefin migration in 8 (entry 5). The generally preferred solvent in $\mathrm{CM}$ reactions such as $\mathrm{CH}_{2} \mathrm{Cl}_{2}$ was not suitable for our synthesis because 8 was insoluble in $\mathrm{CH}_{2} \mathrm{Cl}_{2}$ (entry 6). Olefin migration of $\mathbf{8}$ rather occurred in $\mathrm{CH}_{2} \mathrm{Cl}_{2}$ or toluene under $\mathrm{CM}$ condition. Among the various solvents tested, THF was the most desirable providing the desired CM product in $41 \%$ yields. Finally, controlling the stoichiometry of the substrates $\mathbf{8}$ and $\mathbf{4 b}$, we obtained the best outcome by using 2.0 equivalent of $\mathbf{8}$ and 1.0 equivalent of $\mathbf{4 b}$ (entries 4, 9, and 10). We were pleased to observe that slow addition of Grubbs II catalyst over $3 \mathrm{~h}$ delivered $\mathbf{2 b}$ in $61 \%$ isolated yield (entry 11) [18,19]. 
Table 1. Optimization of cross metathesis reaction ${ }^{\mathrm{a}}$.

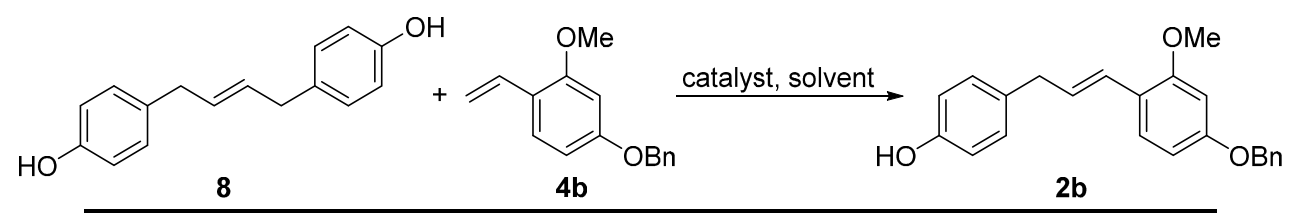

\begin{tabular}{ccccc}
\hline Entry & $\mathbf{8}$ (equiv.) & Catalyst (mol \%) & Solvent & Yield (\%) $^{\mathbf{b}}$ \\
\hline 1 & 2.0 & Grubbs I (2) & THF & NR $^{\mathrm{c}}$ \\
2 & 2.0 & Grubbs II (2) & THF & 9 \\
3 & 2.0 & Hoveyda-Grubbs II (2) & THF & 8 \\
4 & 2.0 & Grubbs II (5) & THF & 41 \\
5 & 2.0 & Grubbs II(10) & THF & 37 \\
6 & 2.0 & Grubbs II (5) & $\mathrm{CH}_{2} \mathrm{Cl}_{2}$ & 4 \\
7 & 2.0 & Grubbs II (5) & DCE & 12 \\
8 & 2.0 & Grubbs II (5) & toluene & 11 \\
9 & 1.0 & Grubbs II (5) & THF & 30 \\
10 & 4.0 & Grubbs II (5) & THF & 36 \\
$\mathbf{1 1}$ & $\mathbf{2 . 0}$ & Grubbs II (5) & THF & $\mathbf{6 1}^{\mathbf{d}}$ \\
\hline
\end{tabular}

${ }^{a}$ Unless otherwise specified, all the reaction were conducted in the presence of $\mathbf{8}, 1.0$ equiv. of $\mathbf{4 b}$, and catalyst at $70{ }^{\circ} \mathrm{C} .{ }^{\mathrm{b}}$ isolated yield. ${ }^{\mathrm{c}}$ No reaction. ${ }^{\mathrm{d}}$ Catalyst was slowly added over $3 \mathrm{~h}$.

Hydrogenation of $\mathbf{2 b}$ with $\mathrm{Pd} / \mathrm{C}$ catalyst furnished $\mathbf{9}$ [20] in 99\% yield to face the final step in the total synthesis of broussonone A (Table 2). We initially anticipated the disparity in electron density of the two aromatic rings would serve as the key controlling factor for the final chemoselective dearomatization step. In recent years, hypervalent iodine reagents such as PIDA, HDIP, and PIFA have been used as oxidative reagents significantly due to their advantages including ready availability, low toxicity, ease of handling, similar activity to heavy metal catalysts, etc. [21-24]. The phenyliodine (III) diacetate (PIDA)-mediated oxidative dearomatization afforded broussonone $\mathrm{A}$ in low yields and mostly many unidentifiable by-products (entry 1). To our delight, replacement of PIDA with phenyliodine (III) bis(trifluoroacetate) (PIFA) accelerated the reaction and the oxidative conversion of B ring reached over $69 \%$ yield (38\% yield of the desired compound 1), while at the same time the reaction accompanied the second dearmoatization to yield $\mathbf{1 2}$ as a major contaminant in over 31\% yield (entry 3). Subsequently, the effects of various solvents were also examined. In $\mathrm{CH}_{3} \mathrm{CN}$ and THF, 12 was identified as the sole major product (entries 4-5). Using $\mathrm{CH}_{3} \mathrm{CN} / \mathrm{H}_{2} \mathrm{O}(2 / 1)$ or acetone as solvents did not improve the ratio of $\mathbf{1}$ and $\mathbf{1 2}$ (entries 1-3). When the reaction was performed in the presence of 1.0 equiv. of PIFA and 1.0 equiv. of 2 in acetone at $0{ }^{\circ} \mathrm{C}$, the best result was obtained to provide broussonone A (1) in $40 \%$ isolated yield along with $31 \%$ yield of 12 (entry 6,71\% combined yield) [25]. It should be noted that the oxidative dearomatization of the protected substrates 10 provided the Ac-protected broussonone A 11 in only 55\% yield. Considering the additional steps for protection and deprotection, our strategy employing the chemoselective oxidative dearomatization in final stage could be considered competitive (Scheme 4). The spectroscopic properties $\left({ }^{1} \mathrm{H}\right.$ - and $\left.{ }^{13} \mathrm{C}-\mathrm{NMR}, \mathrm{HRMS}\right)$ of the synthetic broussonone A were compatible with those of the natural $\mathbf{1}$ [1]. 
Table 2. Optimization of oxidative dearomatization ${ }^{\text {a }}$.

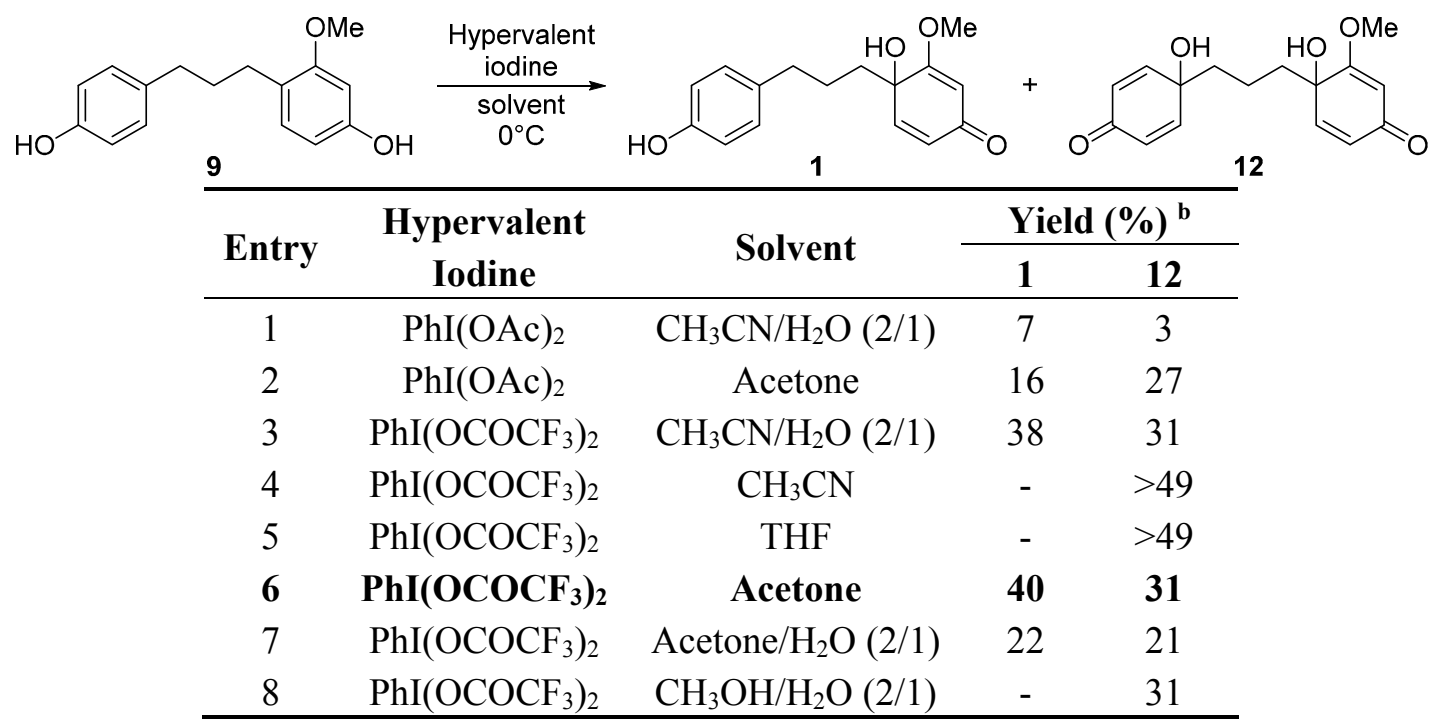

${ }^{\mathrm{a}} 1.0$ equiv. of 9 and 1.0 equiv. of oxidant was used and the reaction was stirred at $0{ }^{\circ} \mathrm{C}$ for $30 \mathrm{~min}$. ${ }^{\mathrm{b}}$ isolated yield.<smiles>C=Cc1ccc(C([In])(Cc2ccccc2)C(F)(F)F)cc1OC</smiles>

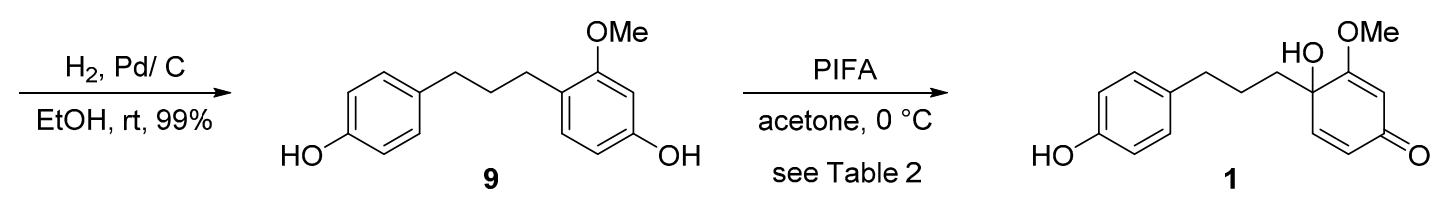<smiles>COc1cc(O)ccc1CCCc1ccc(OC(C)=O)cc1</smiles>

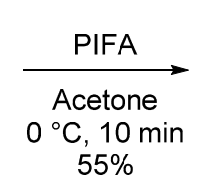

$55 \%$<smiles>COc1ccc(CCCC2(O)C=CC(=O)C=C2OC(C)=O)cc1</smiles>

11

Scheme 4. Completion of total synthesis of $\mathbf{1}$.

\section{Experimental Section}

\subsection{General Information}

All manipulations of compounds were performed under a nitrogen atmosphere. THF were obtained from Sigma Aldrich Co. (St. Louis, MO, USA), purified by dried over fresh Na chips. All reactant or reagent was purchased from Sigma Aldrich Co. or Tokyo Chemical Industry (Tokyo Chemical Industry, Tokyo, Japan), and used without purification. Silica gel column chromatography was performed with Silica Gel of Kieselgel 60 F 254 plate (Merck Millipore Corporation, Darmstadt, Germany). All ${ }^{1} \mathrm{H}-\mathrm{NMR}$ and ${ }^{13} \mathrm{C}-\mathrm{NMR}$ spectra of organic products were recorded on Bruker DPX $400 \mathrm{MHz}$ Spectrometer (Bruker Corporation, Karlsruhe, Germany) and Bruker AVANCE 500 MHz Spectrometer (Bruker Corporation, Karlsruhe, Germany). Data are reported as follows: chemical shift in ppm $(\delta)$, multiplicity (s = singlet, $\mathrm{d}=$ doublet, $\mathrm{t}=$ triplet, $\mathrm{m}=$ multiplet $)$, coupling constant $(\mathrm{Hz})$, and integration . 


\subsection{Synthesis}

4-Allyl phenol (6). 4-Allylanisole $(0.768 \mathrm{~mL}, 5.00 \mathrm{mmol})$ was dissolved in $\mathrm{CH}_{2} \mathrm{Cl}_{2}$ and then $\mathrm{BBr}_{3}$ $(5.50 \mathrm{~mL}, 5.50 \mathrm{mmol})$ was added at $0{ }^{\circ} \mathrm{C}$. Then the mixture was stirred at same temperature for $1 \mathrm{~h}$. After the completion of the reaction, the reaction mixture was quenched with $\mathrm{H}_{2} \mathrm{O}$ and extracted with $\mathrm{CH}_{2} \mathrm{Cl}_{2}$. The combined organic phase were dried with $\mathrm{Na}_{2} \mathrm{SO}_{4}$ and concentrated in vacuo to give a crude product and it was purified by column chromatography on silica gel (EtOAc/hexanes $=1 / 3)$ to afford 4-allylphenol 6 (654 mg, 97.5\%). ${ }^{1} \mathrm{H}-\mathrm{NMR}\left(\mathrm{CDCl}_{3}, 400 \mathrm{MHz}\right) \delta 7.06(\mathrm{~d}, 2 \mathrm{H}, J=8.2 \mathrm{~Hz}), 6.78(\mathrm{~d}, 2 \mathrm{H}$, $J=8.4 \mathrm{~Hz}), 5.95(\mathrm{~m}, 1 \mathrm{H}), 5.07(\mathrm{~m}, 2 \mathrm{H}), 3.33(\mathrm{~d}, 2 \mathrm{H}, J=6.7 \mathrm{~Hz})$.

(E)-4,4'-(But-2-ene-1,4-diyl)diphenol (8). To a stirred solution of 4-allylphenol (6) (327 mg, $2.44 \mathrm{mmol})$ in dried $\mathrm{CH}_{2} \mathrm{Cl}_{2}$ was added Grubbs I catalyst $(40.1 \mathrm{mg}, 48.8 \mathrm{mmol})$ and the mixture was heated at reflux for $4.5 \mathrm{~h}$. The solvent was removed under reduced pressure and purified by column chromatography on silica gel $($ EtOAc/hexanes $=1 / 4)$ to afforddimer $8(256 \mathrm{mg}, 87.3 \%) .{ }^{1} \mathrm{H}-\mathrm{NMR}\left(\mathrm{CD}_{3} \mathrm{OD}, 400 \mathrm{MHz}\right)$ $\delta 6.95(\mathrm{~d}, 4 \mathrm{H}, J=8.5 \mathrm{~Hz}), 6.68(\mathrm{~d}, 2 \mathrm{H}, J=8.5 \mathrm{~Hz}), 5.55(\mathrm{~m}, 2 \mathrm{H}), 3.22(\mathrm{~d}, 4 \mathrm{H}, J=5.0 \mathrm{~Hz}),{ }^{13} \mathrm{C}-\mathrm{NMR}$ $\left(\mathrm{CD}_{3} \mathrm{OD}, 125 \mathrm{MHz}\right) \delta 155.1,131.6,130.3,129.0,114.7,37.6$; $\mathrm{MS} m / z(\mathrm{M}+\mathrm{H})^{+}$calculated for $\mathrm{C}_{16} \mathrm{H}_{16} \mathrm{O}_{2}$ : 240.1; found 240.1 .

4-(Benzyloxy)-2-methoxybenzaldehyde (3a). To a solution of 4-hydroxy-2-methoxybenzaldehyde (3) (200 mg, $1.31 \mathrm{mmol}$ ) in DMF was added $\mathrm{K}_{2} \mathrm{CO}_{3}(543 \mathrm{mg}, 3.93 \mathrm{mmol})$ under $\mathrm{N}_{2}$ atmosphere and mixture was stirred at room temperature for $30 \mathrm{~min}$. $\mathrm{BnBr}(0.312 \mathrm{~mL}, 2.62 \mathrm{mmol})$ was added to reaction mixture and stirred for $1.5 \mathrm{~h}$. After the completion of the reaction, the reaction mixture was diluted with EtOAc and washed with $\mathrm{H}_{2} \mathrm{O}$. The organic phase were dried with $\mathrm{Na}_{2} \mathrm{SO}_{4}$ and concentrated in vacuo purified by column chromatography on silica gel using (EtOAc/hexanes $=1 / 2)$ to afford aldehyde 3a (304 mg, 95.7\%). ${ }^{1} \mathrm{H}-\mathrm{NMR}\left(\mathrm{CDCl}_{3}, 400 \mathrm{MHz}\right) \delta 7.81(\mathrm{~d}, 1 \mathrm{H}, J=8.6 \mathrm{~Hz}), 7.36(\mathrm{~m}, 5 \mathrm{H}), 6.62(\mathrm{dd}, 1 \mathrm{H}, J=8.7,2.2 \mathrm{~Hz}), 6.54$ $(\mathrm{d}, 1 \mathrm{H}, J=2.2 \mathrm{~Hz}), 5.14(\mathrm{~s}, 2 \mathrm{H}), 3.89(\mathrm{~s}, 3 \mathrm{H})$.

4-(Benzyloxy)-2-methoxy-1-vinylbenzene (4b). Under $\mathrm{N}_{2}$ atmosphere, a solution of $t$-BuOK (1.0 M solution in THF, $6.00 \mathrm{~mL}, 6.00 \mathrm{mmol})$ was added methyltriphenylphosphonium bromide $(1.29 \mathrm{~g}, 3.60 \mathrm{mmol})$ at $0{ }^{\circ} \mathrm{C}$ and stirred at room temperature for $30 \mathrm{~min}$. Then, the reaction mixture was cooled to $0{ }^{\circ} \mathrm{C}$ and a solution of $4 \mathbf{a}(291 \mathrm{mg}, 1.20 \mathrm{mmol})$ in dry THF was added to reaction mixture and stirred for $4 \mathrm{~h}$. After the completion of the reaction, the reaction mixture was quenched with saturated $\mathrm{NH}_{4} \mathrm{Cl}$ and extracted with $\mathrm{CH}_{2} \mathrm{Cl}_{2}$. The organic phase were dried with $\mathrm{Na}_{2} \mathrm{SO}_{4}$ and concentrated in vacuo and purified by column chromatography on silica gel $($ EtOAc/hexanes $=1 / 3)$ to afford styrene $\mathbf{4 b}(176 \mathrm{mg}, 61.2 \%)$. ${ }^{1} \mathrm{H}-\mathrm{NMR}\left(\mathrm{CD}_{3} \mathrm{OD}, 400 \mathrm{MHz}\right) \delta 7.35(\mathrm{~m}, 6 \mathrm{H}), 6.90(\mathrm{dd}, 1 \mathrm{H}, J=17.8 \mathrm{~Hz}), 6.53(\mathrm{~m}, 2 \mathrm{H}), 5.57(\mathrm{dd}, 1 \mathrm{H}$, $J=17.8,1.7 \mathrm{~Hz}), 5.04(\mathrm{dd}, 1 \mathrm{H}, J=11.2,1.7 \mathrm{~Hz}), 5.04(\mathrm{~s}, 2 \mathrm{H}), 3.76(\mathrm{~s}, 3 \mathrm{H}) ;{ }^{13} \mathrm{C}-\mathrm{NMR}\left(\mathrm{CD}_{3} \mathrm{OD}\right.$, $125 \mathrm{MHz}) \delta \delta 159.9,157.9,137.3,131.1,128.1,127.5,127.2,126.7,119.8,110.7,105.9,98.7,69.7$, 54.6; MS $m / z(\mathrm{M}+\mathrm{H})^{+}$calculated for $\mathrm{C}_{16} \mathrm{H}_{16} \mathrm{O}_{2}: 240.1$; found 240.1 .

(E)-4-(3-(4-(Benzyloxy)-2-methoxyphenyl)allyl)phenol (2b). To a stirred solution of (E)-4,4'-(but-2-ene1,4-diyl)diphenol (8) (200 mg, $0.832 \mathrm{mmol}$ ) and 4-(benzyloxy)-2-methoxy-1-vinylbenzene (4b) (100 mg, $0.416 \mathrm{mmol})$ in anhydrous THF was added Grubbs II catalyst $(17.7 \mathrm{mg}, 0.416 \mathrm{mmol})$ and the mixture was heated at reflux for $16 \mathrm{~h}$. After the completion of the reaction, the solvent was removed under reduced 
pressure and the resulting residue was subjected to silica gel chromatography $($ EtOAc/hexanes $=1 / 6)$ to afford alkene $\mathbf{2 b}(87.8 \mathrm{mg}, 61.0 \%) .{ }^{1} \mathrm{H}-\mathrm{NMR}\left(\mathrm{CD}_{3} \mathrm{OD}, 400 \mathrm{MHz}\right) \delta 7.43-7.27(\mathrm{~m}, 6 \mathrm{H}), 7.01(\mathrm{~d}, 2 \mathrm{H}$, $J=8.6 \mathrm{~Hz}), 6.69(\mathrm{~d}, 2 \mathrm{H}, J=8.6 \mathrm{~Hz}), 6.55(\mathrm{~m}, 3 \mathrm{H}), 6.16(\mathrm{~m}, 1 \mathrm{H}), 5.05(\mathrm{~s}, 2 \mathrm{H}), 3.78(\mathrm{~s}, 3 \mathrm{H}), 3.38(\mathrm{~d}, 2 \mathrm{H}$, $J=6.0 \mathrm{~Hz}) ;{ }^{13} \mathrm{C}-\mathrm{NMR}\left(\mathrm{CDCl}_{3}, 100 \mathrm{MHz}\right) \delta 159.2,157.5,153.8,136.9,133.0,129.7,128.6,128.2$, $128.0,127.5,127.2,125.1,119.9,115.2,105.7,99.4,70.2,55.5,39.0 ; \mathrm{MS} m / z(\mathrm{M}+\mathrm{H})^{+}$calculated for $\mathrm{C}_{23} \mathrm{H}_{22} \mathrm{O}_{3}$ : 346.2; found 346.2.

4-(3-(1-Hydroxy-2-methoxy-4-oxocyclohexa-2,5-dien-1-yl)propyl)phenyl acetate (11). To a solution of 4-(3-(4-hydroxy-2-methoxyphenyl)propyl)phenyl acetate (10) $(30 \mathrm{mg}, 0.10 \mathrm{mmol})$ in acetone $(0.5 \mathrm{~mL})$ at $0{ }^{\circ} \mathrm{C}$ was treated with PIFA (43 mg, $0.1 \mathrm{mmol}$ ) and stirred for $10 \mathrm{~min}$ at $0{ }^{\circ} \mathrm{C}$. After the completion of the reaction, the reaction mixture was diluted with $\mathrm{CH}_{2} \mathrm{Cl}_{2}$ and washed with saturated $\mathrm{NaHCO}_{3}$ solution. The aqueous phase was extracted with $\mathrm{CH}_{2} \mathrm{Cl}_{2}$. The combined organic extracts were dried with $\mathrm{Na}_{2} \mathrm{SO}_{4}$, concentrated in vacuo and purified by column chromatography on silica gel (EtOAc/hexanes $=1 / 1)$ to afford $p$-quinol $11(17 \mathrm{mg}, 55 \%) .{ }^{1} \mathrm{H}-\mathrm{NMR}\left(\mathrm{CD}_{3} \mathrm{OD}, 400 \mathrm{MHz}\right) \delta 7.11(\mathrm{~d}, 2 \mathrm{H}, J=8.6 \mathrm{~Hz}), 6.98(\mathrm{~d}, 2 \mathrm{H}$, $J=8.5 \mathrm{~Hz}), 6.57(\mathrm{~d}, 1 \mathrm{H}, J=10.0 \mathrm{~Hz}), 6.16(\mathrm{dd}, 1 \mathrm{H}, J=10.0,1.6 \mathrm{~Hz}), 5.51(\mathrm{~d}, 1 \mathrm{H}, J=1.6 \mathrm{~Hz}), 3.75(\mathrm{~s}$, $3 \mathrm{H}), 2.55(\mathrm{~m}, 2 \mathrm{H}), 2.28(\mathrm{~s}, 3 \mathrm{H}), 1.95(\mathrm{~m}, 1 \mathrm{H}), 1.80(\mathrm{~m}, 1 \mathrm{H}), 1.37(\mathrm{~m}, 1 \mathrm{H}), 0.84(\mathrm{~m}, 1 \mathrm{H})$; HRMS m/z $(\mathrm{M}+\mathrm{H})^{+}$calculated for $\mathrm{C}_{18} \mathrm{H}_{20} \mathrm{O}_{5}: 317.1384$; found 317.1386 .

4-(3-(4-Hydroxyphenyl)propyl)-3-methoxyphenol (9). To a solution of alkene $\mathbf{2 b}$ (101 $\mathrm{mg}, 0.292 \mathrm{mmol})$ and $10 \% \mathrm{Pd} / \mathrm{C}(12.4 \mathrm{mg}, 0.117 \mathrm{mmol})$ in $\mathrm{EtOH}$, hydrogen gas was fluxed for $10 \mathrm{~min}$ at room temperature. The reaction mixture was stirred under $\mathrm{H}_{2}$ atmosphere for $16 \mathrm{~h}$ at room temperature, then filtered over Celite, the solvent was discarded and the residue purified by column chromatography on silica gel (EtOAc/hexanes $=1 / 6)$, to afford phenol $9(74.7 \mathrm{mg}, 99.0 \%) .{ }^{1} \mathrm{H}-\mathrm{NMR}\left(\mathrm{CD}_{3} \mathrm{OD}, 400 \mathrm{MHz}\right) \delta 6.95(\mathrm{~d}$, $2 \mathrm{H}, J=8.5 \mathrm{~Hz}), 6.84(\mathrm{~d}, 1 \mathrm{H}, J=8.1 \mathrm{~Hz}), 6.66(\mathrm{~d}, 2 \mathrm{H}, J=8.5 \mathrm{~Hz}), 6.36(\mathrm{~d}, 1 \mathrm{H}, J=2.3 \mathrm{~Hz}), 6.27(\mathrm{dd}$, $1 \mathrm{H}, J=8.1,2.3 \mathrm{~Hz}), 3.73(\mathrm{~s}, 3 \mathrm{H}), 2.47(\mathrm{~m}, 4 \mathrm{H}), 1.75(\mathrm{~m}, 2 \mathrm{H}) ;{ }^{13} \mathrm{C}-\mathrm{NMR}\left(\mathrm{CD}_{3} \mathrm{OD}, 125 \mathrm{MHz}\right) \delta 158.3$, $156.3,154.8,133.4,129.7,128.8,121.4,114.6,106.1,98.4,54.2,34.4,32.2,28.9 ; \mathrm{HRMS} m / z(\mathrm{M}+\mathrm{H})^{+}$ calculated for $\mathrm{C}_{16} \mathrm{H}_{18} \mathrm{O}_{3}$ : 259.1334; found 259.1316 .

Broussonone $A$ (1). To a solution of 4-(3-(4-hydroxyphenyl)propyl)-3-methoxyphenol (9) (26.0 mg, $0.10 \mathrm{mmol})$ in acetone $(1.0 \mathrm{~mL})$ at $0{ }^{\circ} \mathrm{C}$ was treated with PIFA $(42.0 \mathrm{mg}, 0.10 \mathrm{mmol})$ and stirred for $30 \mathrm{~min}$ at $0{ }^{\circ} \mathrm{C}$. The reaction mixture was diluted with $\mathrm{CH}_{2} \mathrm{Cl}_{2}$ and washed with saturated $\mathrm{NaHCO}_{3}$ solution. The aqueous phase was extracted with $\mathrm{CH}_{2} \mathrm{Cl}_{2}$. The combined organic extracts were dried with $\mathrm{Na}_{2} \mathrm{SO}_{4}$, concentrated in vacuo and purified by column chromatography on silica gel $\left(5 \% \mathrm{MeOH}\right.$ in $\left.\mathrm{CH}_{2} \mathrm{Cl}_{2}\right)$ to afford the synthetic broussonone A (1) $(11.0 \mathrm{mg}, 40 \%) .{ }^{1} \mathrm{H}-\mathrm{NMR}\left(\mathrm{CD}_{3} \mathrm{OD}, 500 \mathrm{MHz}\right) \delta 6.91(\mathrm{~d}, 2 \mathrm{H}$, $J=8.5 \mathrm{~Hz}), 6.66(\mathrm{~d}, 2 \mathrm{H}, J=8.5 \mathrm{~Hz}), 6.61(\mathrm{~d}, 1 \mathrm{H}, J=10.0 \mathrm{~Hz}), 6.07(\mathrm{dd}, 1 \mathrm{H}, J=10.0 \mathrm{~Hz}, 1.7 \mathrm{~Hz}), 5.52$ $(\mathrm{d}, 1 \mathrm{H}, J=1.7 \mathrm{~Hz}), 3.76(\mathrm{~s}, 3 \mathrm{H}), 2.46(\mathrm{~m}, 2 \mathrm{H}), 1.95(\mathrm{~m}, 1 \mathrm{H}), 1.70(\mathrm{~m}, 1 \mathrm{H}), 1.49(\mathrm{~m}, 2 \mathrm{H}) ;{ }^{13} \mathrm{C}-\mathrm{NMR}$ $\left(\mathrm{CD}_{3} \mathrm{OD}, 125 \mathrm{MHz}\right) \delta \delta 188.8,177.1,155.1,148.7,132.4,128.9,126.7,114.7,100.7,70.8,55.2,37.6$, 34.2, 25.3; HRMS $m / z(\mathrm{M}+\mathrm{H})^{+}$calculated for $\mathrm{C}_{16} \mathrm{H}_{18} \mathrm{O}_{4}$ : 274.1267; found 274.1267.

For more details of NMR spectra, please see Supplementary Materials Figures S1-S17. 


\section{Conclusions}

In summary, we have successfully demonstrated the first total synthesis of broussonone A in three steps from the known compound $4 \mathbf{b}$ with a $24 \%$ overall yield. The key features of this synthetic route involve the following: (1) the Grubbs II catalyst mediated cross metathesis of two aromatic subunits; (2) the chemoselective oxidative dearomatization in the presence of two phenol moieties. These studies provide a timely contribution to the development of a practical synthetic approach to a variety of broussonone A analogues. With this practical synthesis of broussonone A now in hand, the intensive exploration of the absolute configuration of the broussonone $\mathrm{A}$ as well as its structural analogues will be extended.

\section{Supplementary Materials}

Supplementary materials can be accessed at: http://www.mdpi.com/1420-3049/20/09/15966/s1.

\section{Acknowledgments}

This research was supported by the Medical Research Center Program (2008-0062275), the research grant of Chungbuk National University in 2012, the National Research Foundation of Korea (NRF) funded by the Ministry of Education, Science and Technology (NRF-2012R1A1A2038433) (to Y.-S.K.) and the Ministry of Land, Transport and Maritime Affairs, Korea (to Y.-J.L.).

\section{Author Contributions}

H.J., M.C., M.V., and Y.H.L. performed the experiments and analyzed all data. Y.-S.K. and H.L conceived and designed the experiments, K.L., N.S.C., and Y.-J.L. analyzed the HRMS data. J.T.H. and M.K.L. suggested the research work. J.-K.J. conceived and directed the investigations and composed the manuscript with revisions provided by the other authors. All authors read and approved the manuscript.

\section{Conflicts of Interest}

The authors declare no conflict of interest.

\section{References and Notes}

1. Ahn, J.H.; Liu, Q.; Lee, C.; Ahn, M.J.; Yoo, H.S.; Hwang, B.Y.; Lee, M.K. A new pancreatic lipase inhibitor from Broussonetia kanzinoki. Bioorg. Med. Chem. Lett. 2012, 22, 2760-2763.

2. Ahn, J.H.; Shin, E.; Liu, Q.; Kim, S.B.; Choi, K.M.; Yoo, H.S.; Hwang, B.Y.; Lee, M.K. Secoiridoids from the stem barks of Fraxinus rhynchophylla with pancreatic lipase inhibitory activity. Nat. Prod. Res. 2013, 27, 1132-1135.

3. Andrae-Marobela, K.; Ghislain, F.W.; Okatch, H.; Majinda, R.R.T. Polyphenols: A Diverse Class of Multi-Target Anti-HIV-1 Agents. Curr. Drug Metab. 2013, 14, 392-413.

4. Kato, E.; Nakagomi, R.; Gunawan-Puteri, M.D.P.T.; Kawabata, J. Identification of hydroxychavicol and its dimers, the lipase inhibitors contained in the Indonesian spice, Eugenia polyantha. Food Chem. 2013, 136, 1239-1242. 
5. Kato, E.; Yama, M.; Nakagomi, R.; Shibata, T.; Hosokawa, K.; Kawabata, J. Substrate-like water soluble lipase inhibitors from Filipendula kamtschatica. Bioorg. Med. Chem. Lett. 2012, 22, 6410-6412.

6. Cui, M.; Li, Z.; Tang, R.; Jia, H.; Liu, B. Novel (E)-5-styryl-2,2'-bithiophene derivatives as ligands for $\beta$-amyloid plaques. Eur. J. Med. Chem. 2011, 46, 2908-2916.

7. Grice, C.A.; Tays, K.L.; Savall, B.M.; Wei, J.; Butler, C.R.; Axe, F.U.; Bembenek, S.D.; Fourie, A.M.; Dunford, P.J.; Lundeen, K.; et al. Identification of a Potent, Selective, and Orally Active Leukotriene A4 Hydrolase Inhibitor with Anti-Inflammatory Activity. J. Med. Chem. 2008, 51, 4150-4169.

8. With electron-deficient aldehyde such as nitrobenzaldehyde, the reaction occurred efficiently with $\mathbf{5}$.

9. Grubbs, R.H. Handbook of Metathesis; Wiley-VCH: Weinheim, Germany, 2003; Volumes 1-3.

10. Alcaide, B.; Almendros, P.; Luna, A. Grubbs' Ruthenium-Carbenes Beyond the Metathesis Reaction: Less Conventional Non-Metathetic Utility. Chem. Rev. 2009, 109, 3817-3858.

11. Lozano-Vila, A.M.; Monsaert, S.; Bajek, A.; Verpoort, F. Ruthenium-Based Olefin Metathesis Catalysts Derived from Alkynes. Chem. Rev. 2010, 110, 4865-4909.

12. Cannon, J. S.; Grubbs, R.H. Alkene Chemoselectivity in Ruthenium-Catalyzed Z-Selective Olefin Metathesis. Angew. Chem. Int. Ed. 2013, 52, 9001-9004.

13. Kingsbury, J.S.; Harrity, J.P.A.; Bonitatebus, P.J.; Hoveyda, A.H. A Recyclable Ru-Based Metathesis Catalyst. J. Am. Chem. Soc. 1999, 121, 791-799.

14. Garber, S.B.; Kingsbury, J.S.; Gray, B.L.; Hoveyda, A.H. Efficient and Recyclable Monomeric and Dendritic Ru-Based Metathesis Catalysts. J. Am. Chem. Soc. 2000, 122, 8168-8179.

15. Tzeng, S.-C.; Liu, Y.-C. Peroxidase-catalyzed synthesis of neolignan and itsanti-inflammatory activity. J. Mol. Catal. B: Enzym. 2004, 32, 7-13.

16. Chatterjee, A.K.; Choi, T.L.; Sanders, D.P.; Grubbs, R.H. A General Model for Selectivity in Olefin Cross Metathesis. J. Am. Chem. Soc. 2003, 125, 11360-11370.

17. Gresser, M.J.; Wales, S.M.; Keller, P.A. The attempted stereoselective synthesis of chiral 2,2'-biindoline. Tetrahedron 2010, 66, 6965-6976.

18. Previously, the ortho-alkoxy- $\beta$-methyl styrenes instead of the simple ortho-alkoxystyrenes have been used for this type CM reactions, see: Strych, S.; Trauner, D. Biomimetic Synthesis of Santalin A,B and Santarubin A,B, the Major Colorants of Red Sandalwood. Angew. Chem. Int. Ed. 2013, 52, 9509-9512.

19. Chatterjee, A.K.; Toste, D.; Choi, T.-L.; Grubbs, R.H. Ruthenium-Catalyzed Olefin Cross Metathesis of Styrenes as an Alternative to the Heck and Cross-Coupling Reactions. Adv. Synth. Catal. 2002, 344, 634-637.

20. Compound 9 is also known as broussonin B of which the only synthetic study was reported, see: de Almeida, P.A.; Fraiz, S.V.; Braz-Filho, R. Synthesis and Structural Confirmation of Natural 1,3-Diarylpropanes. J. Braz. Chem. Soc. 1999, 10, 347-353.

21. Rappoport, Z. The Chemistry of Phenols; Wiley: Chichester, UK, 2003; Volumes 1-2.

22. Hata, K.; Hamamoto, H.; Shiozaki, Y.; Cammerer, S.B.; Kita, Y. Nucleophilic attack of intramolecular hydroxyl groups onelectron-rich aromatics using hypervalent iodine(III) oxidation. Tetrahedron 2007, 63, 4052-4060.

23. Plourde, G.L. Studies towards the diastereoselective spiroannulation of phenolic derivatives. Tetrahedron Lett. 2002, 43, 3597-3599.

24. Felpin, F.X. Oxidation of 4-arylphenol trimethylsilyl ethers to $p$-arylquinols using hypervalent iodine(III) reagents. Tetrahedron Lett. 2007, 48, 409-412. 
25. The Oxone-mediated oxidative dearomitization of the corresponding ketone-contaning phenol has been reported, see: Barrada, S.; Hernandez-Torres, G.; Urbano, A.; Carreno, M.C. Total Synthesis of Natural p-Quinol. Org. Lett. 2012, 14, 5952-5955.

Sample Availability: Sample of the compound $\mathbf{1}$ is available from the authors.

(C) 2015 by the authors; licensee MDPI, Basel, Switzerland. This article is an open access article distributed under the terms and conditions of the Creative Commons Attribution license (http://creativecommons.org/licenses/by/4.0/). 